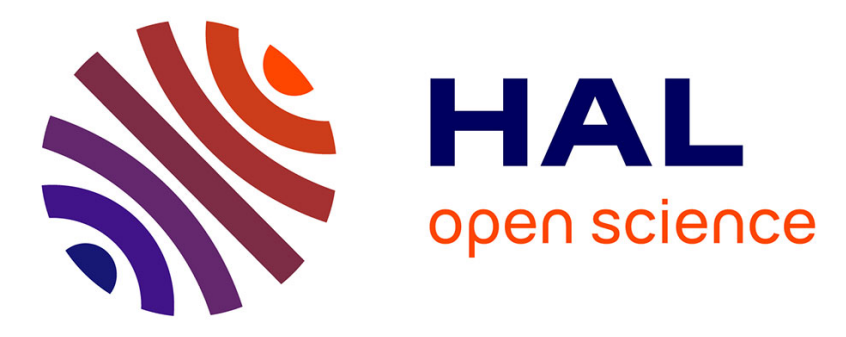

\title{
Ultrasound-induced gas release from contrast agent microbubbles
}

\author{
Michiel Postema, Ayache Bouakaz, Michel Versluis, Nico de Jong
}

\section{To cite this version:}

Michiel Postema, Ayache Bouakaz, Michel Versluis, Nico de Jong. Ultrasound-induced gas release from contrast agent microbubbles. IEEE Transactions on Ultrasonics, Ferroelectrics and Frequency Control, 2005, 52 (6), pp.1035-1041. 10.1109/TUFFC.2005.1504026 . hal-03193382

\section{HAL Id: hal-03193382 \\ https://hal.science/hal-03193382}

Submitted on 13 Apr 2021

HAL is a multi-disciplinary open access archive for the deposit and dissemination of scientific research documents, whether they are published or not. The documents may come from teaching and research institutions in France or abroad, or from public or private research centers.
L'archive ouverte pluridisciplinaire HAL, est destinée au dépôt et à la diffusion de documents scientifiques de niveau recherche, publiés ou non, émanant des établissements d'enseignement et de recherche français ou étrangers, des laboratoires publics ou privés. 


\title{
Ultrasound-induced Gas Release from Contrast
}

\section{Agent Microbubbles}

\author{
Michiel Postema, Member, IEEE, Ayache Bouakaz, Michel Versluis, \\ Nico de Jong, Associate Member, IEEE
}

\begin{abstract}
We investigated gas release from two hard-shelled ultrasound contrast agents, by subjecting them to high-MI ultrasound and simultaneously capturing high-speed photographs. At an insonifying frequency of $1.7 \mathrm{MHz}$, a larger percentage of contrast bubbles is seen to crack than at $0.5 \mathrm{MHz}$. Most of the released gas bubbles have equilibrium diameters between 1.25 and $1.75 \mu \mathrm{m}$. Their disappearance was observed optically. Free gas bubbles have equilibrium diameters smaller than the bubbles from which they have been released. Coalescence may account for the long dissolution times acoustically observed and published in previous studies. After sonic cracking, the cracked bubbles stay acoustically active.
\end{abstract}

\section{INTRODUCTION}

Sonic cracking is the ultrasound-induced release of gas from hard-shelled microbubbles [1]. This phenomenon has been observed in insonified contrast agent with the aid of high-speed photography [2], [3], [4], [5]. The following clinical applications of sonic cracking have been suggested [4]:

Imaging applications. Release burst imaging makes use of the strong scattering response of released gas microbubbles [6]. While the free gas dissolves, the strong acoustic response fades away. The measurement of the reappearance of contrast microbubbles is a quantitative perfusion indicator [7].

This work has been supported by the Technology Foundation STW (RKG.5104).

M. Postema, A. Bouakaz, and N. de Jong are with the Department of Experimental Echocardiography, Thoraxcentre, Erasmus MC, Rotterdam, The Netherlands (e-mail: m.postema@erasmusmc.nl) and also with the Interuniversity Cardiology Institute of the Netherlands (ICIN), Utrecht, The Netherlands.

M. Versluis and N. de Jong are with the Physics of Fluids Group, Faculty of Science and Technology, University of Twente, Enschede, The Netherlands.

Current address M. Postema: Audiological Center, Department of Otorhinolaryngology, Erasmus MC, Rotterdam, The Netherlands. M. Postema is also with the Department of Neuroscience, Erasmus MC, Rotterdam, The Netherlands.

Current address A. Bouakaz: INSERM 619, Université François-Relais, Tours, France. 
Drug delivery. If the gas content of the encapsulated bubble has therapeutic properties, sonic cracking may find an application in localized drug delivery. We think of nitric oxide and gaseous anaesthetics. The released gas bubbles might be targeted to the vessel wall owing to primary radiation forces [4], [8]. The behavior of contrast agent microbubbles near cells has been recently studied by Van Wamel, Kudo, and Wolfrum [9], [10], [11], [12].

Noninvasive blood pressure measurements. When a free gas bubble dissolves into a liquid medium, its acoustic response changes with its radius. ${ }^{1}$ The changes in oscillating behavior of the dissolving gas bubble lead to changes in scattering cross sections [14], and thus, the scattering behavior of an insonified, diffusing gas bubble can be calculated, dependent of the applied overpressure. Hence, a noninvasive method for blood pressure assessment would be the measurement of the acoustic response from a dissolving bubble population [15].

For all applications, a contrast agent consisting of hard-shelled bubbles acts as a vehicle that carries a gas compound to a region of interest ( $c f$. Fig. 1). The gas compound is released by a high-MI ultrasonic burst. The dissolving gas compound is tracked by a low-MI ultrasonic signal. A low-MI signal can also be used to induce microbubble translation [8]. The mechanical index is defined by:

$$
\mathrm{MI}=\frac{p_{\mathrm{ac}}^{-}}{\sqrt{f}},
$$

where $p_{\mathrm{ac}}^{-}$is the peak rarefactional acoustic pressure normalized by $1 \mathrm{MPa}$ and $f$ is the center frequency of the ultrasound normalized by $1 \mathrm{MHz}$.

Especially for the latter two potential applications, the gas release has to be controlled. In this study, we take a step towards controlled gas release from hard-shelled microbubbles, by visualizing and quantifying gas release under different conditions. Furthermore, we discuss if the sizes of the released gas bubbles are in agreement with previous measurements of acoustic decay times.

\section{THEORY}

The dissolving time of released gas bubbles is related to the hydrostatic pressure as follows [15]:

$$
\frac{\mathrm{d} R}{\mathrm{~d} t}=D L\left(\frac{\frac{C_{\mathrm{i}}}{C_{0}}-1-\frac{2 \sigma}{R p_{0}}-\frac{p_{\mathrm{ov}}}{p_{0}}}{1+\frac{4 \sigma}{3 R p_{0}}}\right)\left(\frac{1}{R}+\frac{1}{\sqrt{\pi D t}}\right),
$$

${ }^{1}$ The resonance frequency $f_{\mathrm{r}}$ of a free gas bubble is related to its diameter $\mathcal{D}$ according to [13]:

$$
f_{\mathrm{r}} \approx \frac{6.5 \mathrm{~m} \mathrm{~s}^{-1}}{\mathcal{D}} \text {. }
$$


where $\frac{C_{\mathrm{i}}}{C_{0}}$ is the ratio of the dissolved gas concentration to the saturation concentration (saturation ratio), $D$ is the diffusion constant, $L$ is the Ostwald coefficient, $p_{0}$ is the ambient pressure, $p_{\text {ov }}$ is the applied overpressure, $R$ is the instantaneous bubble radius, $t$ is the time starting $(t=0)$ when the bubble surface is exposed to the liquid surface, and $\sigma$ is the surface tension. Equation (2) shows that the disappearance of gas bubbles in a liquid medium is highly influenced by gas diffusion parameters and applied overpressure, and that the disappearance time of gas bubbles is shorter when the liquid medium is under pressure. Simulations of dissolving gas bubbles were presented in [15], [16], [17], [18].

\section{EXPERIMENTAL SETUP}

\section{Overview}

For the observations of gas release, we made use of the Brandaris-128 fast framing camera system [19]. An overview of this experimental setup is shown in Figure 2. The amplitude of the electrical signal generated by an AWG 520 arbitrary waveform generator (Tektronix, Inc., Beaverton, OR) was adjusted by two variable 355C/D attenuators (Hewlett Packard Company, Palo Alto, CA) in series, and an A-500 $60 \mathrm{~dB}$ linear power amplifier (ENI technology, Inc., Rochester, NY). The signal was converted to ultrasound by a v389-SU $500 \mathrm{kHz}$ (focal width $3 \mathrm{~mm}$ ), or by a v397-su $2.25 \mathrm{MHz}$ single-element transducer (focal width $1 \mathrm{~mm}$ ) (Panametrics Inc., Waltham, MA), both spherically focused at $7.5 \mathrm{~cm}$. The transducer was mounted in a Perspex container at an angle of $45^{\circ}$ relative to the top of the container ( $c f$.

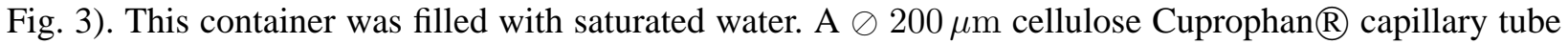
(Membrana $\mathrm{GmbH}$, Wuppertal, Germany) was fixed in the focal area of the transducer, through which contrast agent was flowing.

\section{Optics}

Underneath the capillary tube an optic fiber was mounted. This fiber was connected to an MVS-7010 Fiber Optic Strobe (PerkinElmer Optoelectronics, Salem, MA), and to a KLS-201 continuous fiber light source (Olympus KMI (KeyMed Ltd), Southend-on-Sea, UK).

The container was positioned beneath a customized BXFM microscopic system (Olympus Optical Co., Ltd., Tokyo, Japan) with a U-CA magnification changer (Olympus Optical Co., Ltd.), switched to $2 \times$ magnification and a LUMPlanFl 60× water immersion objective lens (Olympus Optical Co., Ltd.). For image control purposes, an LCL-902K CCD camera (Watec Co., Ltd., Yamagata, Japan) was mounted to the top of the microscope. 


\section{Camera}

The optical observations of the situation during gas release and of the situation $100 \mathrm{~ms}$ after insonification were recorded with a Brandaris-128 ( $c f$. Figure 4) fast framing camera system [19]. The Brandaris-128 captured sequences of 128 image frames at speeds up to 25 million frames per second. Typical frame sizes correspond to $89 \times 68 \mu \mathrm{m}^{2}$. In all observations, image frames were captured before, during, and after ultrasound insonification.

For the observations of the gas dissolution process itself ( $c f$. Fig. 8), which is a relatively slow process compared to bubble oscillations, we also made use of a data set recorded with a CR 2000 camera (Redlake MASD, LLC, San Diego, CA) that operated at a speed of two thousand frames per second. This camera had been installed on top of the microscope, as shown in Figure 4.

\section{Contrast agents}

We investigated the ultrasound contrast agent Quantison ${ }^{\mathrm{TM}}$ (Upperton Limited). It consists of human serum albumin-encapsulated air bubbles with a mean diameter of $3.2 \mu \mathrm{m}$. Shell thicknesses are between 0.2 and $0.3 \mu \mathrm{m}$ [20]. The resonance frequency of the bulk agent is $4 \mathrm{MHz}$ [20]. The content of a Quantison $^{\mathrm{TM}}$ vial was resuspended in $5 \mathrm{ml}$ of Isoton ${ }^{\circledR}$ II (Beckman Coulter, Inc., Fullerton, CA), and shaken gently for 20 seconds before further dilution (approximately 1:50). Further dilution ensures that only a few freely flowing contrast agent microbubbles are in the optical focal plane in the field of view.

We also investigated PB127 (POINT Biomedical Corporation, San Carlos, CA), which is specified as follows: PB127 consists of bilayered microspheres encapsulating nitrogen bubbles with a mean diameter of $4 \mu \mathrm{m}$. The outermost layer is albumin and the inner layer is composed of a biodegradable polymer. The resonance frequency of PB127 lies between 6 and $7 \mathrm{MHz}$. The content of a PB127 vial was resuspended in $2 \mathrm{ml}$ of deionized water, and shaken gently for 20 seconds before further dilution (approximately 1:50).

The pressure field exerted by an oscillating contrast microbubble depends on the volumetric acceleration of the bubble [21], [22]. For hard-shelled contrast microbubbles this pressure is very low compared to the ultrasonic field. Hence, for the concentrations we use, the presence of neighboring hard-shelled bubbles is negligible.

\section{Ultrasound}

The agents were insonified either by 8 cycles of $500 \mathrm{kHz}$ ultrasound at peak rarefactional pressures $p_{\text {ac }}^{-}$ in the range $0.2<p_{\mathrm{ac}}^{-}<1.3 \mathrm{MPa},{ }^{2}$ or by 8 cycles of $1.7 \mathrm{MHz}$ ultrasound at peak rarefactional pressures

\footnotetext{
${ }^{2}$ or by 6 cycles in the recordings with the CR 2000 camera. An example of such a recording is given in Fig. 8 .
} 
in the range $0.4<p_{\mathrm{ac}}^{-}<2.5 \mathrm{MPa}$. For both frequencies transmitted, peak rarefactional acoustic pressures were equivalent to mechanical indices in the range $0.3<\mathrm{MI}<1.9$. We refer to ultrasound transmission with mechanical indices greater than 0.8 as high-MI insonification. Acoustic pressures in this regime are high enough to ensure gas release [23]. This is the regime where other destruction mechanisms have been observed with encapsulated bubbles, such as fragmentation and jetting [4]. Sonic cracking is expected to increase with MI. Since it is used in clinical settings, and has to be comparable to other studies, we use the MI as a measure to compare sonic cracking under different frequencies.

Acoustic pressures applied were measured with a calibrated (for both frequencies) MH28-10 PVDF needle hydrophone (FORCE Technology, Brøndby, Denmark) in a separate water tank.

\section{Procedure}

We recorded 533 image sequences with the Brandaris-128 system, and 55 sequences with the Kodak CR 2000 camera. For each event, the total number of contrast agent microbubbles visible in the frames were counted, and the number of contrast agent microbubbles from which gas was released. In total, we counted 428 released bubbles. From the frames recorded after ultrasound insonification, the diameters of the released gas bubbles (if still present) or fragments thereof were measured, as well as the diameters of the contrast agent microbubbles from which they had escaped. Fifty eight resting diameters of released PB127 gas bubbles were measured. Bubble diameters and distances were measured manually or by using an image processing method described in [24].

\section{RESULTS}

\section{Quantison $^{T M}$}

An example of the sonic cracking of a Quantison ${ }^{\mathrm{TM}}$ bubble is shown in Figure 5. Frames numbering is from left to right, then from upper to lower. The camera system operated at a speed of 10 million frames per second. Gas is seen to escape from a $\oslash 4.3 \mu \mathrm{m}$ shelled Quantison ${ }^{\mathrm{TM}}$ bubble in the third frame, owing to the rarefaction phase of the driving ultrasound. Apparently, the Quantison ${ }^{\mathrm{TM}}$ shell is too rigid to be seen expanded. The free gas expands to $\oslash 12.3 \mu \mathrm{m}$ in the eighth frame, after which it contracts. In the eleventh frame, the free gas bubble, which has been subjected to motion blur, appears to be detached from the shelled bubble. In the twelfth frame, the gas is hardly visible, owing to the compressive phase of the driving ultrasound.

Another example of gas release is given in Figure 6. The camera system operated at a speed of 3 million frames per second. In the second frame, gas escapes from a $\oslash 3.7 \mu \mathrm{m}$ bubble. The response of 
the released gas to ultrasound can be clearly appreciated. After expanding to a $\oslash 8.0 \mu \mathrm{m}$ maximum in frame three, it is seen detached and contracted in frames four and five. The encapsulated bubble clearly looks different than before cracking, as if there is no gas left inside the shell. A few microseconds after insonification, the left frame of Figure 7 was captured. The released gas bubble is visible to the upper left of the bubble from which we saw it escape. Its diameter is estimated to be less than $1 \mu \mathrm{m}$. One hundred ms later, the right frame was captured. Here, the released gas bubble has disappeared.

The dissolving process itself of the released gas bubbles was captured at 2000 frames per second. The upper images of Figure 8 show 8-bit photographs of three Quantison ${ }^{\mathrm{TM}}$ bubbles before ultrasound arrival. The lower images show the same photographs after gray-level window-slicing. After insonification, the Quantison $^{\mathrm{TM}}$ bubbles have translated, and two fragments are visible in the second frame. The diameters of the fragments are less than $1 \mu \mathrm{m}$. These fragments slowly disappear, and are hardly visible in the last frame.

$P B 127$

An example of the sonic cracking of PB127 bubbles is shown in Figure 9, at MI=0.9 and a driving frequency of $1.7 \mathrm{MHz}$. Frames numbering is from left to right, then from upper to lower. The camera system operated at a speed of 9.4 million frames per second. Upon ultrasound arrival in the second frame, two $\oslash 7 \mu \mathrm{m}$ PB127 bubbles start to contract. From frame four on, gas is released from both bubbles. In frame eight, both gas bubbles have been detached from the shell. Starting with frame ten, gas release is again observed from the lower PB127 bubble. The released gas bubbles interact, and both fragmentation and coalescence occur several times between frames 21 and 47. After insonification had finished, one resulting free gas bubble remained, which was still seen to pulsate. The left frame of Figure 10 was captured after insonification. The free gas bubble is the lower bubble in the diamond-shaped bubble group. Its resting diameter is $4 \mu \mathrm{m}$. One hundred ms later, the right frame was captured. Here, the free gas bubble has disappeared.

Our results show that the sizes of the PB127 bubbles from which gas was released, are normally distributed. The mean diameter of these bubbles is $3.6 \mu \mathrm{m}$, with a standard deviation of $1.5 \mu \mathrm{m}$.

The size distribution of the released gas bubbles from PB127 is shown in Figure 11. For both frequencies, most released gas bubbles have equilibrium diameters between 1.25 and $1.75 \mu \mathrm{m}$. We did not find a correlation between the sizes of the released gas bubbles and the peak acoustic pressures. 


\section{Overview}

A quantitative overview of gas release is demonstrated in Figure 12. Typically, 10-15 contrast agent bubbles were visible in the field of view. For both agents, the percentage of released gas bubbles is greater at $1.7 \mathrm{MHz}$ than at $0.5 \mathrm{MHz}$ insonification.

Released gas bubbles have been observed to translate, to fragment, and to coalesce with other released bubbles. The contrast agent bubbles did not demonstrate these phenomena. Our measurements of resting sizes of released gas bubbles include fragments of released gas bubbles and coalesced bubbles. Bubbles that did not show gas release upon insonification, have been observed to crack during a subsequent ultrasonic burst.

After sonic cracking, contrast bubbles of both agents can stay acoustically active. Gas remainder has been observed inside the shells from sonically cracked bubbles, which was released by a subsequent ultrasonic burst.

\section{DisCUSSION AND CONCLUSIONS}

We can only speculate on why certain bubbles crack while others stay intact. Tiny flaws in the shells may account for this observation. Such flaws are apparently formed or widened during ultrasound insonification, causing the bubble to crack during a subsequent ultrasonic burst. The partly emptied shell must still be traceable after sonic cracking, and might have different acoustic properties. This is the first study where subsequent gas release was witnessed from the same contrast agent microbubble. This is also the first study where ulltrasound-induced coalescence of released gas bubbles has been observed.

The difference in average cracking percentage observed at $0.5 \mathrm{MHz}$ and $1.7 \mathrm{MHz}$, may lie in the proximity of the resonance frequency of the agent to the insonifying frequency. The resonance frequency of Quantison $^{\mathrm{TM}}$ is closest to $1.7 \mathrm{MHz}$, indeed. So is the resonance frequency of PB127: $f_{\mathrm{r}}>1.7 \mathrm{MHz}$. This would imply that at a driving frequency closer to the resonance frequency (given the same MI), sonic cracking would be observed more often.

The phenomenon of bubbles translating during an ultrasonic cycle has only been observed in our results with free gas bubbles, and not with the hard-shelled bubbles. We attribute this behavior to the small size of the free gas bubbles during contraction, and the lack thereof with the hard-shelled contrast agent bubbles. When in contraction phase, free gas bubbles have a very small translating mass, as it is equivalent to half the mass of the displaced fluid [25]. When subjected to a radiation force, such light bubbles can accelerate much faster than the relatively heavy encapsulated bubbles. 
The mean diameter of the PB127 bubbles from which gas was released, agrees with the published mean diameter of PB127 bubbles, but the free gas bubbles have final resting diameters smaller than the bubbles from which they have been released. The observations of gas left inside shell after cracking, may account for this difference.

The acoustic response from an ensemble of Quantison ${ }^{\mathrm{TM}}$ microbubbles disappears between 15 and $30 \mathrm{~ms}$ after transmission of a high-MI ultrasonic burst [15], whereas the disappearance time of the fundamental acoustic response of an ensemble of PB127 microbubbles is shorter than $100 \mathrm{~ms}$ after transmission of a high-amplitude ultrasonic burst [23]. Figure 13 demonstrates simulations of the dissolution of nitrogen microbubbles with diameters between 0.5 and $4.5 \mu \mathrm{m}$ into saturated water at ambient pressure. For the environment of a blood vessel, the saturation ratio of the gas will be different from the (saturated) in vitro situation. However, this difference in dissolution time for nitrogen is low (a few ms) compared to the dissolution time itself (10-100 ms). To overcome this difference, it has been suggested by us that one might use noble gases for released microbubble-based pressure measurements, so that the saturation ratio is zero [18]. Since most released gas bubbles have equilibrium diameters between 1.25 and $1.75 \mu \mathrm{m}$, they will disappear within $15 \mathrm{~ms}$. The longer decay times measured in Quantison ${ }^{\mathrm{TM}}$ [15] and PB127 [23] must be attributed to the relatively small number of large released gas bubbles around $4 \mu \mathrm{m}$ (dissolution in $90 \mathrm{~ms}$ ). These large bubbles might be formed by coalescence of released gas bubbles or fragments. The mechanism of ultrasound-induced lipid-encapsulated microbubble coalescence was recently studied [26]. Ultrasound-induced coalescence of released gas microbubbles is currently under investigation [27].

For noninvasive pressure measurements, the influence of applying hydrostatic overpressures on the occurrence of sonic cracking will have to be investigated. Furthermore, the influence of pulse length and pulse repetition are of great practical interest.

\section{ACKNOWLEDGMENTS}

We thank POINT Biomedical Corporation for supplying PB127, Upperton Limited for supplying Quantison $^{\mathrm{TM}}$, Leo Bekkering and Jan Honkoop for technical assistance, and Cees Pakvis for drawing Figure 4.

\section{REFERENCES}

[1] Y. Takeuchi, IEEE Trans. Ultrason., Ferroelect., Freq. Contr., vol. 46, no. 4, p. cover, 1999.

[2] P. Dayton, K. Morgan, M. Allietta, A. Klibanov, G. Brandenburger, and K. Ferrara, "Simultaneous optical and acoustical observations of contrast agents," Proc. IEEE Ultrason. Symp., pp. 1583-1591, 1997. 
[3] M. Postema, A. Bouakaz, C. T. Chin, and N. de Jong, "Optically observed microbubble coalescence and collapse," Proc. IEEE Ultrason. Symp., pp. 1900-1903, 2002.

[4] M. Postema, A. van Wamel, C. T. Lancée, and N. de Jong, "Ultrasound-induced encapsulated microbubble phenomena," Ultrasound Med. Biol., vol. 30, no. 6, pp. 827-840, 2004.

[5] S. H. Bloch, M. Wan, P. A. Dayton, and K. W. Ferrara, "Optical observation of lipid- and polymer-shelled ultrasound microbubble contrast agents," Appl. Phys. Lett., vol. 84, no. 4, pp. 631-633, 2004.

[6] P. J. A. Frinking, Ultrasound Contrast Agents: acoustic characterization and diagnostic imaging. Rotterdam: PJA Frinking, 1999.

[7] K. Wei, A. R. Jayaweera, S. Firoozan, A. Linka, D. M. Skyba, and S. Kaul, "Quantification of myocardial blood flow with ultrasound-induced destruction of microbubbles administered as a constant venous infusion," Circulation, vol. 97, pp. 473-483, 1998.

[8] M. J. Shortencarier, P. A. Dayton, S. H. Bloch, P. A. Schumann, T. O. Matsunaga, and K. W. Ferrara, "A method for radiation-force localized drug delivery using gas-filled lipospheres," IEEE Trans. Ultrason., Ferroelect., Freq. Contr., vol. 51, no. 7, pp. 822-831, 2004.

[9] A. van Wamel, A. Bouakaz, F. ten Cate, and N. de Jong, "Effects of diagnostic ultrasound parameters on molecular uptake and cell viability," Proc. IEEE Ultrason. Symp., pp. 1387-1390, 2002.

[10] N. Kudo, T. Miyaoka, K. Niwa, and K. Yamamoto, "Optical observation of cell-bubble behavior using a high-speed camera," Abstr. 7th Eur. Symp. Ultrasound Contrast Imaging, pp. 70-71, 2002.

[11] N. Kudo, T. Miyaoka, K. Okada, K. Yamamoto, and K. Niwa, "Study on mechanism of cell damage caused by microbubbles exposed to ultrasound," Proc. IEEE Ultrason. Symp., pp. 1351-1354, 2002.

[12] B. Wolfrum, R. Mettin, T. Kurz, and W. Lauterborn, "Observations of pressure-wave-excited contrast agent bubbles in the vicinity of cells," Appl. Phys. Lett., vol. 81, no. 26, pp. 5060-5062, 2002.

[13] M. Minnaert, "On musical air bubbles and the sound of running water," Philos. Mag., no. S. 16, pp. $235-248,1933$.

[14] S. Hilgenfeldt, D. Lohse, and M. Zomack, "Sound scattering and localized heat deposition of pulse-driven microbubbles," J. Acoust. Soc. Am., vol. 107, no. 6, pp. 3530-3539, 2000.

[15] A. Bouakaz, P. J. A. Frinking, N. de Jong, and N. Bom, "Noninvasive measurement of the hydrostatic pressure in a fluid-filled cavity based on the disappearance time of micrometer-sized free gas bubbles," Ultrasound Med. Biol., vol. 25, no. 9, pp. 1407-1415, 1999.

[16] A. Kabalnov, D. Klein, T. Pelura, E. Schutt, and J. Weers, "Dissolution of multicomponent microbubbles in the bloodstream: 1. Theory," Ultrasound Med. Biol., vol. 24, no. 5, pp. 739-749, 1998.

[17] W. S. Chen, T. J. Matula, and L. A. Crum, "The disappearance of ultrasound contrast bubbles: observations of bubble dissolution and cavitation nucleation," Ultrasound Med. Biol., vol. 28, no. 6, pp. 793-803, 2002.

[18] M. Postema, A. Bouakaz, and N. de Jong, "Noninvasive microbubble-based pressure measurements: a simulation study," Ultrasonics, vol. 42, no. 1-9, pp. 759-762, 2004.

[19] C. T. Chin, C. Lancée, J. Borsboom, F. Mastik, M. Frijlink, N. de Jong, M. Versluis, and D. Lohse, "Brandaris 128: a 25 million frames per second digital camera with 128 highly sensitive frames," Rev. Sci. Instru., vol. 74, no. 12, pp. 5026-5034, 2003.

[20] P. J. A. Frinking and N. de Jong, "Acoustic modeling of shell-encapsulated gas bubbles," Ultrasound Med. Biol., vol. 24, no. 4, pp. 523-533, 1998.

[21] L. D. Landau and E. M. Lifshitz, Fluid Mechanics, 2nd ed. Oxford: Pergamon Press, 1987. 
[22] M. A. B. Postema, Medical Bubbles. Bergschenhoek: Michiel Postema, 2004.

[23] P. N. Burns, R. Karshafian, P. Bevan, N. de Jong, A. Bouakaz, C. T. Chin, M. Versluis, and G. Tickner, "Looking at and listening to breaking bubbles: a correlative optical acoustic study of some experimental polymer/air agents," Abstr. 9th Eur. Symp. Ultrasound Contrast Imaging, pp. 11-16, 2004.

[24] M. Postema, A. Bouakaz, C. T. Chin, and N. de Jong, "Simulations and measurements of optical images of insonified ultrasound contrast microbubbles," IEEE Trans. Ultrason., Ferroelect., Freq. Contr., vol. 50, no. 5, pp. 523-536, 2003.

[25] T. G. Leighton, The Acoustic Bubble. London: Academic Press Ltd, 1994.

[26] M. Postema, P. Marmottant, C. T. Lancée, S. Hilgenfeldt, and N. de Jong, "Ultrasound-induced microbubble coalescence," Ultrasound Med. Biol., vol. in press, 2004.

[27] M. Postema, P. Marmottant, C. T. Lancée, M. Versluis, S. Hilgenfeldt, and N. de Jong, "Ultrasound-induced coalescence of free gas microbubbles," Proc. IEEE Ultrason. Symp., vol. in press, 2004. 


\section{LIST OF FIGURES}

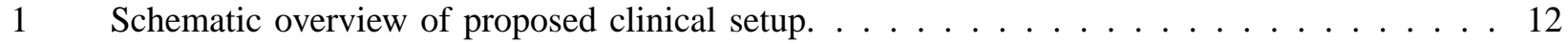

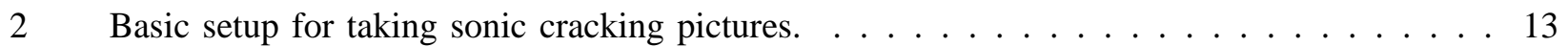

3 Overview of the optical/ultrasound part of the experimental bubble-system. . . . . . . . . 14

4 Line drawings of the housing of the Brandaris-128 (left) and the CR 2000 camera (right). . 15

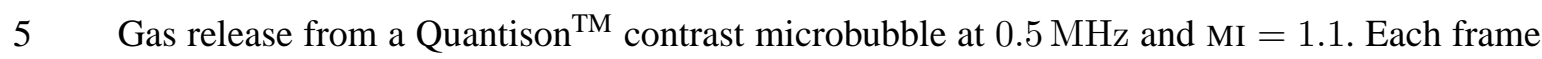
corresponds to a $19 \times 19 \mu \mathrm{m}^{2}$ area. Interframe times are $0.1 \mu \mathrm{s}$. The frames cover the second

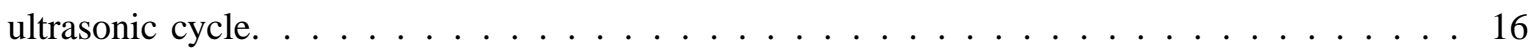

6 Gas release from a Quantison ${ }^{\mathrm{TM}}$ contrast microbubble at $0.5 \mathrm{MHz}$ and $\mathrm{MI}=0.9$. Each frame corresponds to a $13 \times 13 \mu \mathrm{m}^{2}$ area. Interframe times are $0.33 \mu \mathrm{s}$. The frames cover

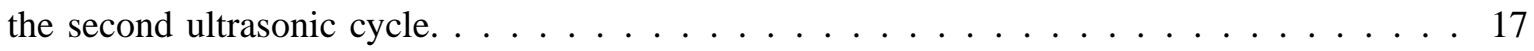

7 Dissolution of released gas. Each frame corresponds to a $13 \times 13 \mu \mathrm{m}^{2}$ area. Time between recordings is $100 \mathrm{~ms}$. The free gas bubble is visible to the upper left of the PB127 bubble

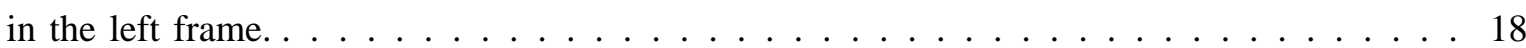

8 Dissolution of released gas, captured at $2 \mathrm{kHz}$. Upper frames show raw CCD images, lower frames show segmented images. Each frame corresponds to a $10 \times 10 \mu \mathrm{m}^{2}$ area. The released gas fragments (arrow) are less than $1 \mu \mathrm{m} \ldots \ldots \ldots \ldots \ldots$

9 Gas release from two PB127 contrast microbubbles (arrows) at $1.7 \mathrm{MHz}$ and $\mathrm{MI}=0.9$. Each frame corresponds to a $46 \times 30 \mu \mathrm{m}^{2}$ area. Interframe times are $0.1 \mu \mathrm{s}$. After release (first three rows), the free gas bubbles interact, until one free gas bubble remains (last row). . . . 20

10 Three PB127 bubbles and one released gas bubble (left). After $100 \mathrm{~ms}$ the released gas bubble has disappeared (right). Each frame corresponds to a $23 \times 23 \mu \mathrm{m}^{2}$ area. Time between

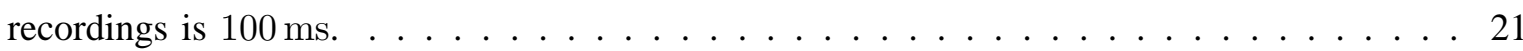

11 Size distribution of released gas from PB127 for $\mathrm{MI}>0.3 \ldots \ldots \ldots \ldots$

12 Average number of cracked contrast agent bubbles for MI>0.8. . . . . . . . 23

13 Dissolution of nitrogen microbubbles with diameters between 0.5 and $4.5 \mu \mathrm{m}$ into saturated

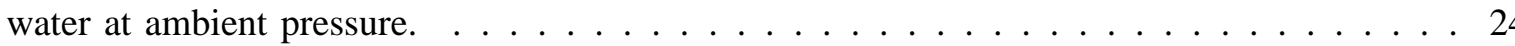




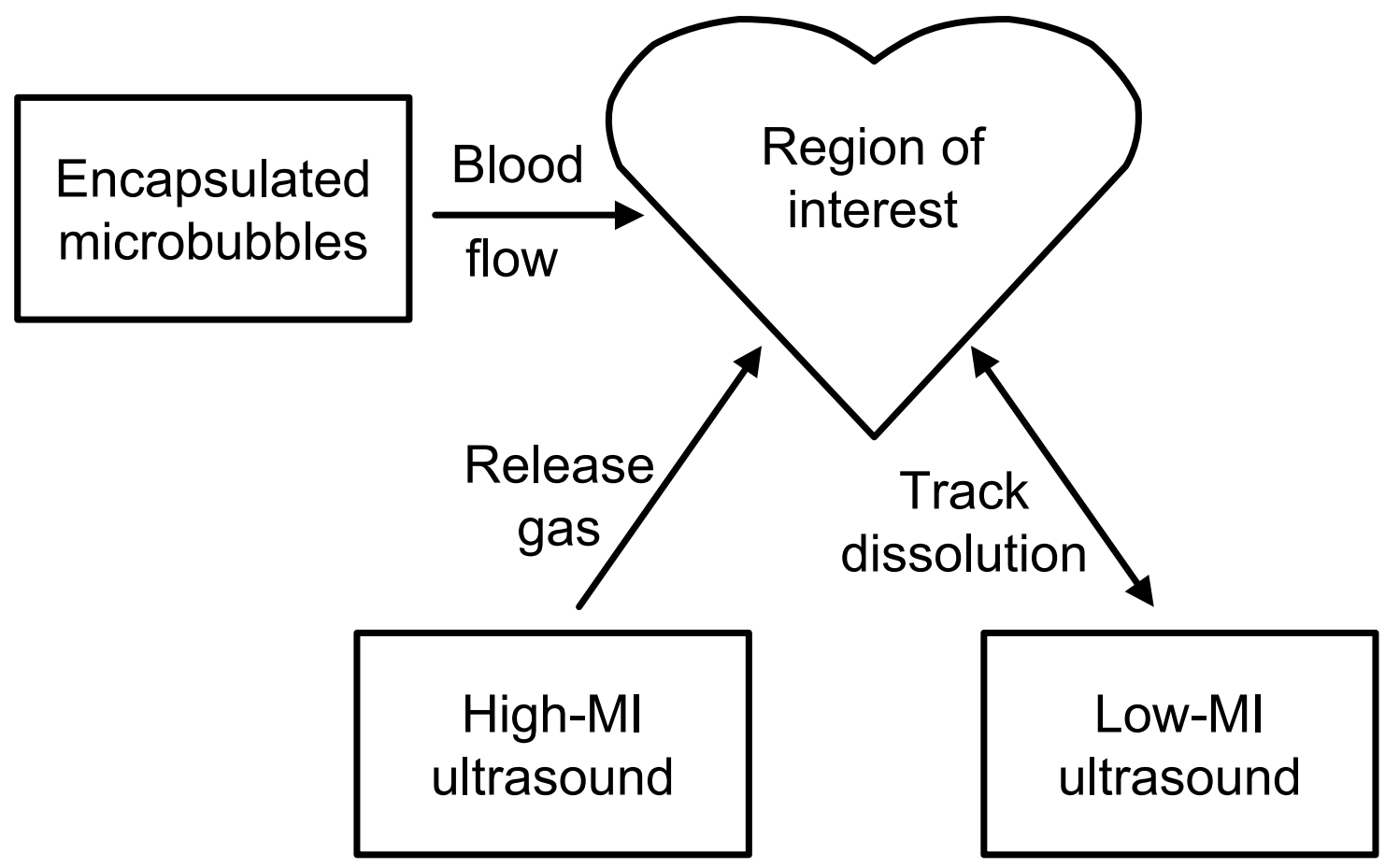

Fig. 1. Schematic overview of proposed clinical setup. 


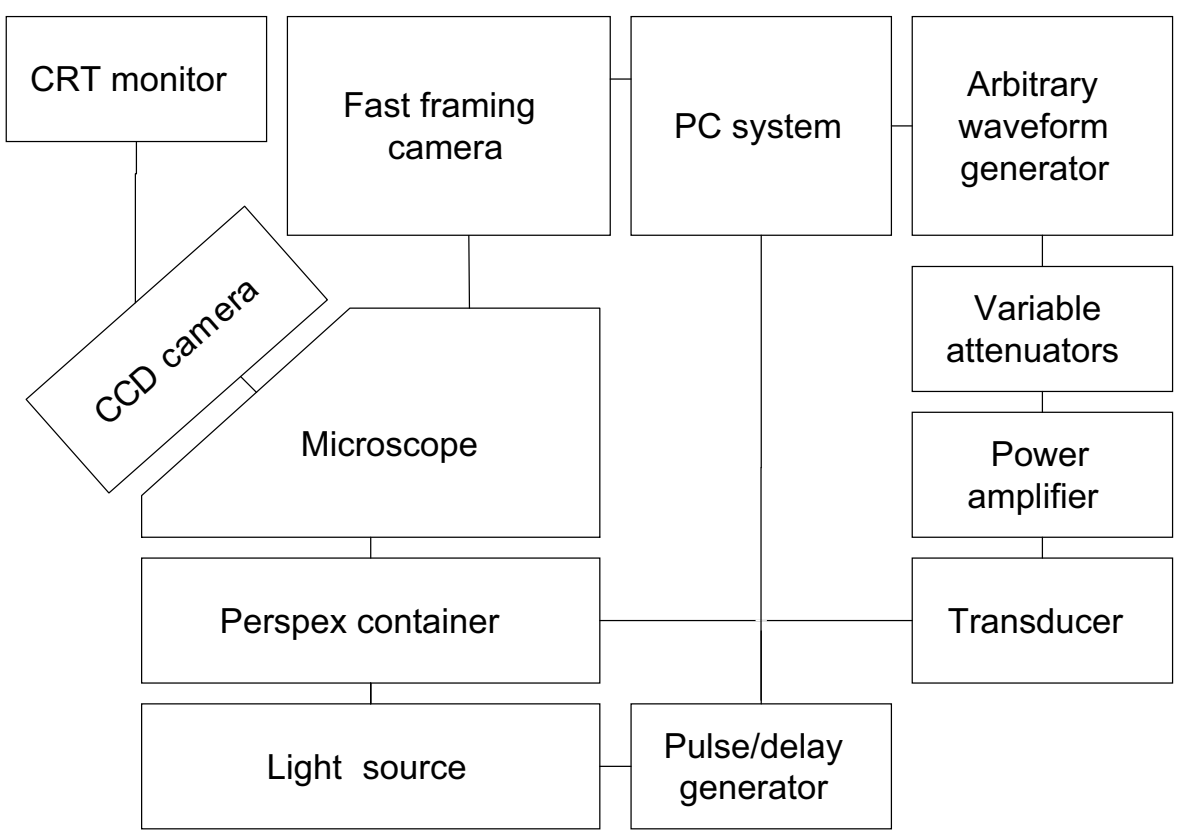

Fig. 2. Basic setup for taking sonic cracking pictures. 


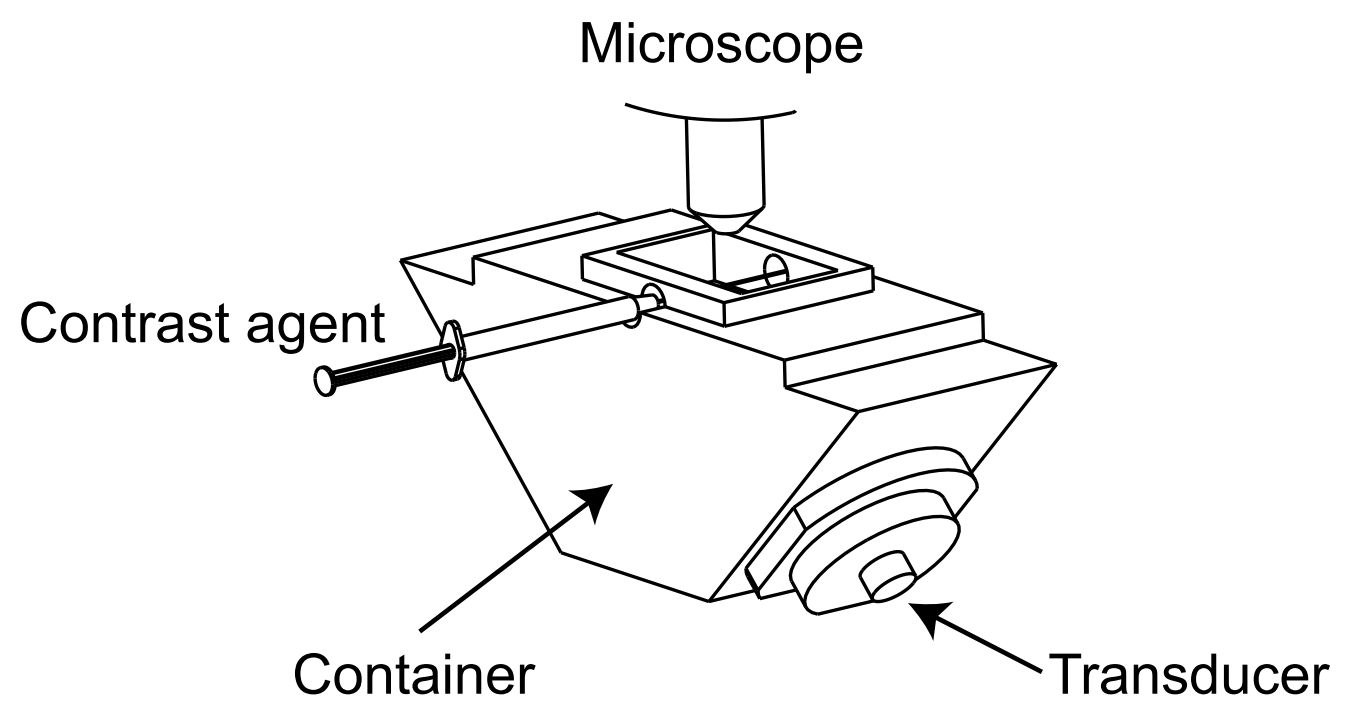

Fig. 3. Overview of the optical/ultrasound part of the experimental bubble-system. 


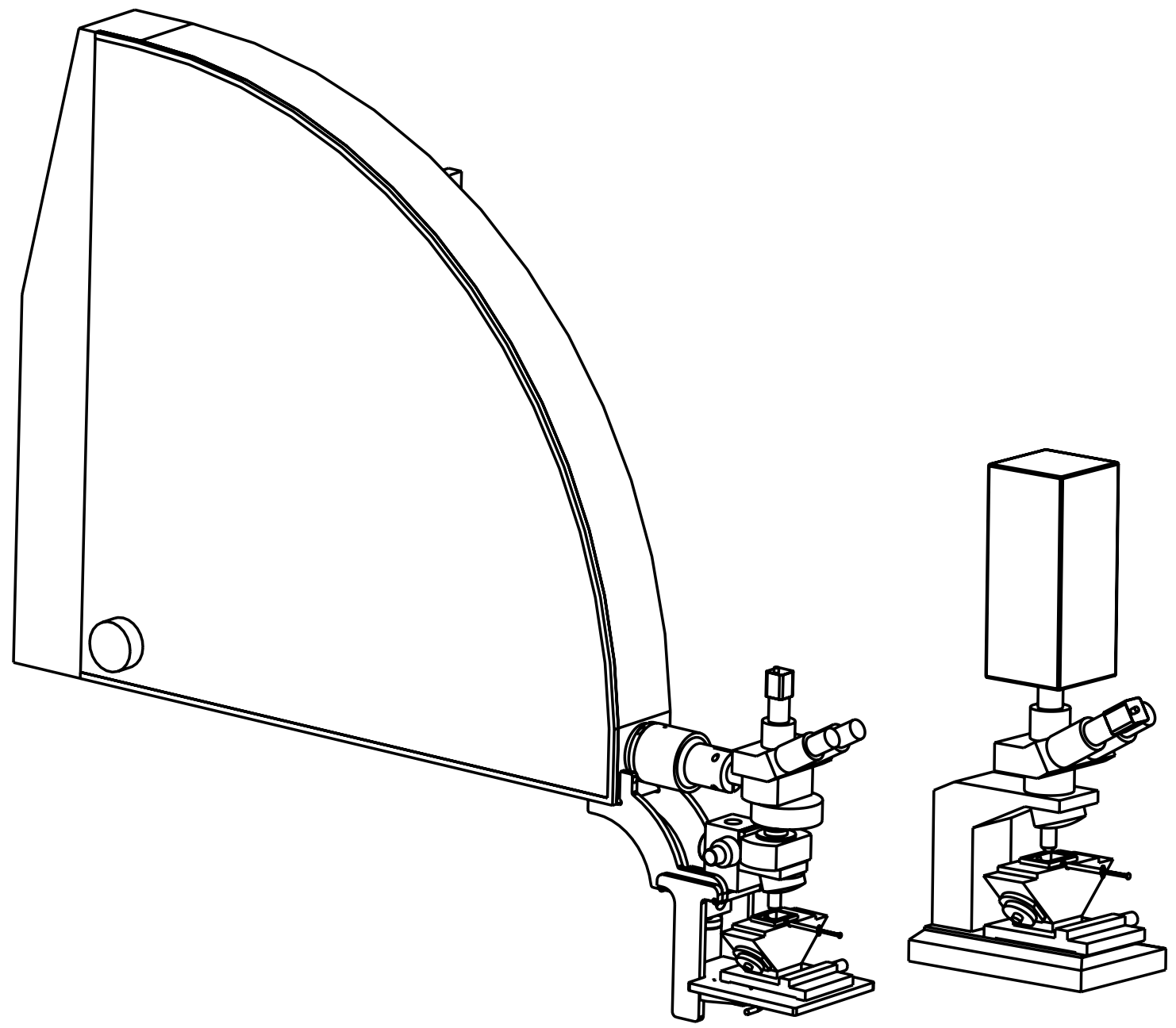

Fig. 4. Line drawings of the housing of the Brandaris-128 (left) and the CR 2000 camera (right). 


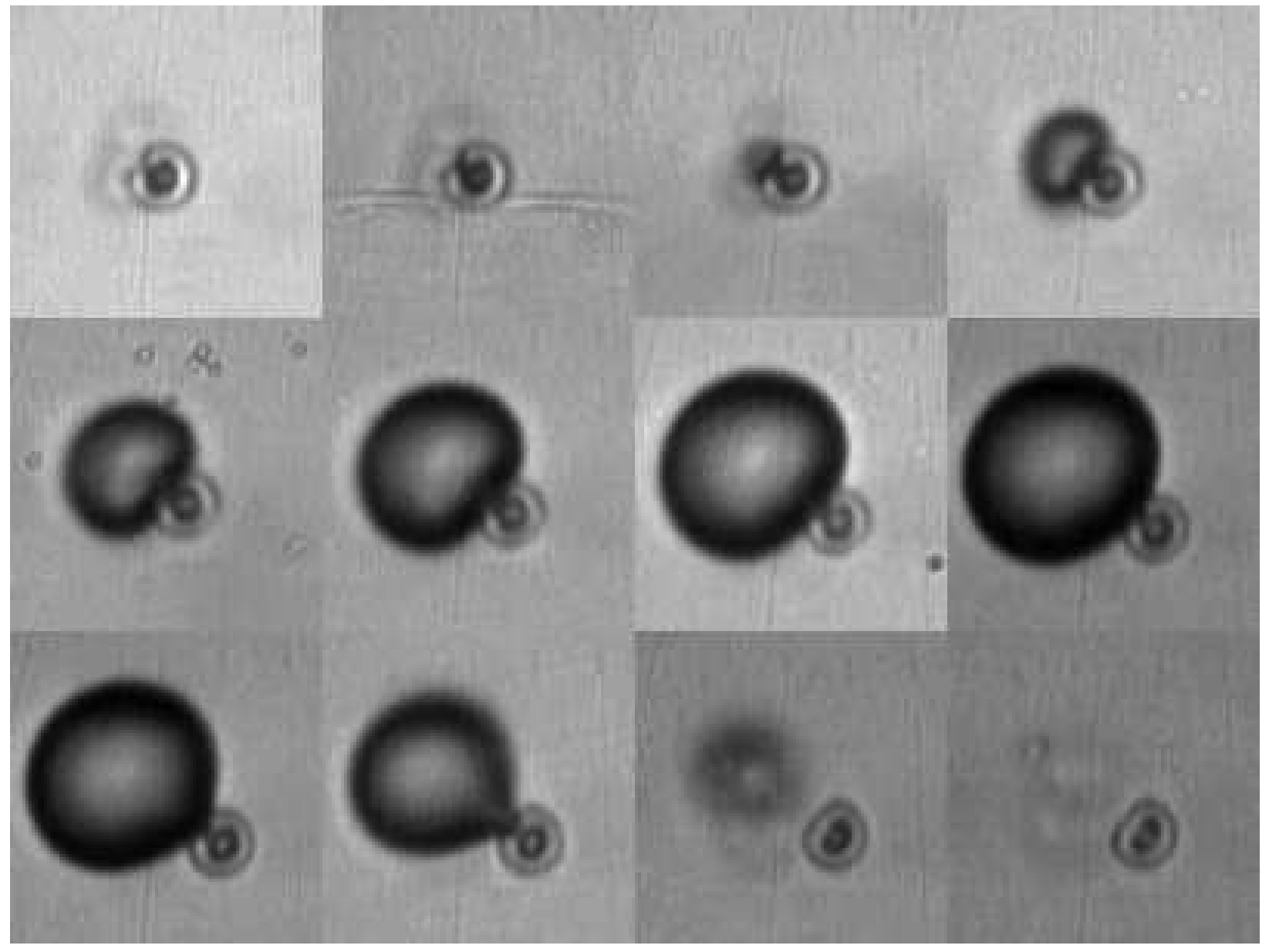

Fig. 5. Gas release from a Quantison ${ }^{\mathrm{TM}}$ contrast microbubble at $0.5 \mathrm{MHz}$ and $\mathrm{MI}=1.1$. Each frame corresponds to a $19 \times 19 \mu \mathrm{m}^{2}$ area. Interframe times are $0.1 \mu \mathrm{s}$. The frames cover the second ultrasonic cycle. 


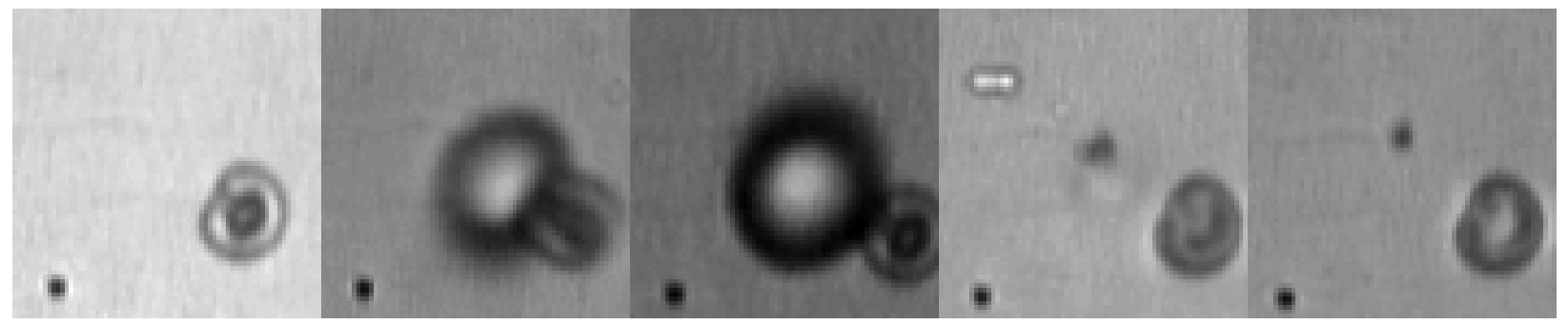

Fig. 6. Gas release from a Quantison ${ }^{\mathrm{TM}}$ contrast microbubble at $0.5 \mathrm{MHz}$ and $\mathrm{MI}=0.9$. Each frame corresponds to a $13 \times 13 \mu \mathrm{m}^{2}$ area. Interframe times are $0.33 \mu \mathrm{s}$. The frames cover the second ultrasonic cycle. 


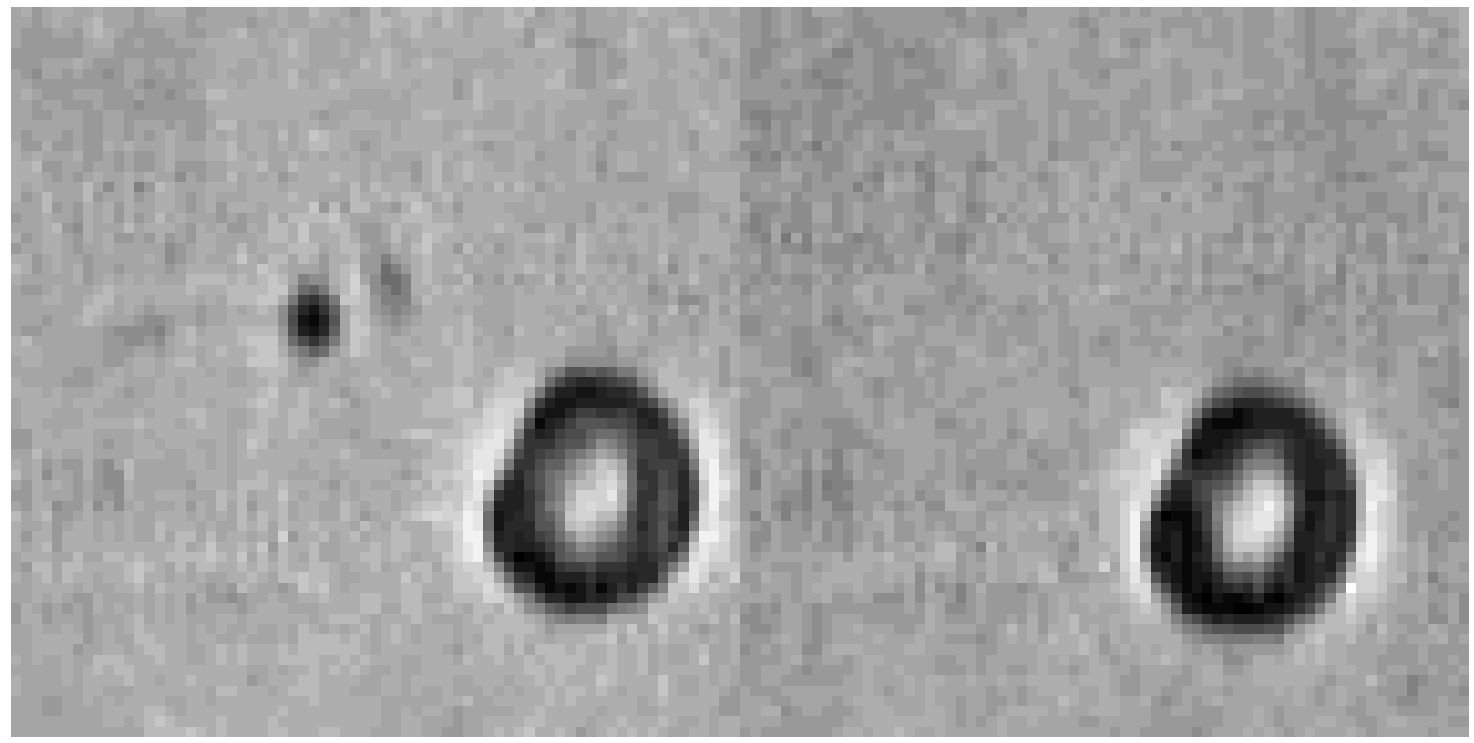

Fig. 7. Dissolution of released gas. Each frame corresponds to a $13 \times 13 \mu \mathrm{m}^{2}$ area. Time between recordings is $100 \mathrm{~ms}$. The free gas bubble is visible to the upper left of the PB127 bubble in the left frame. 

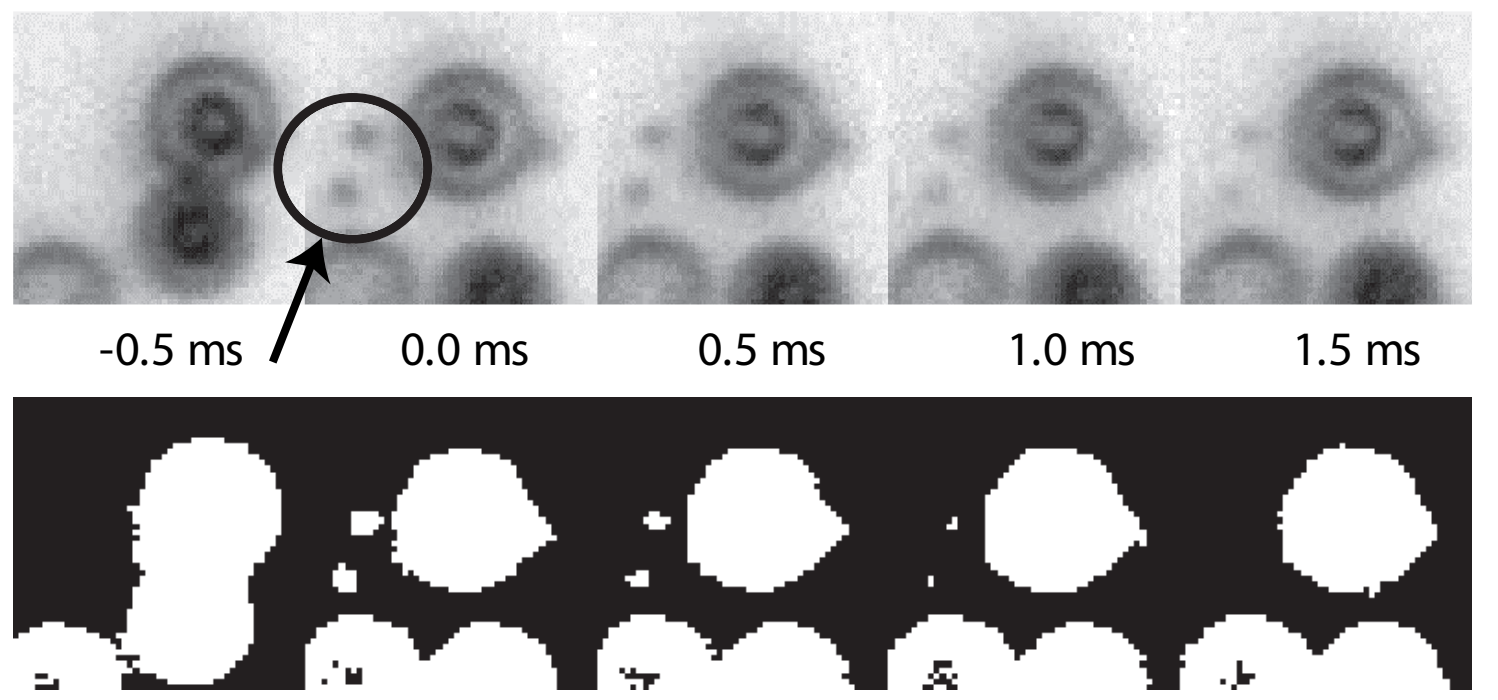

Fig. 8. Dissolution of released gas, captured at $2 \mathrm{kHz}$. Upper frames show raw CCD images, lower frames show segmented images. Each frame corresponds to a $10 \times 10 \mu \mathrm{m}^{2}$ area. The released gas fragments (arrow) are less than $1 \mu \mathrm{m}$. 


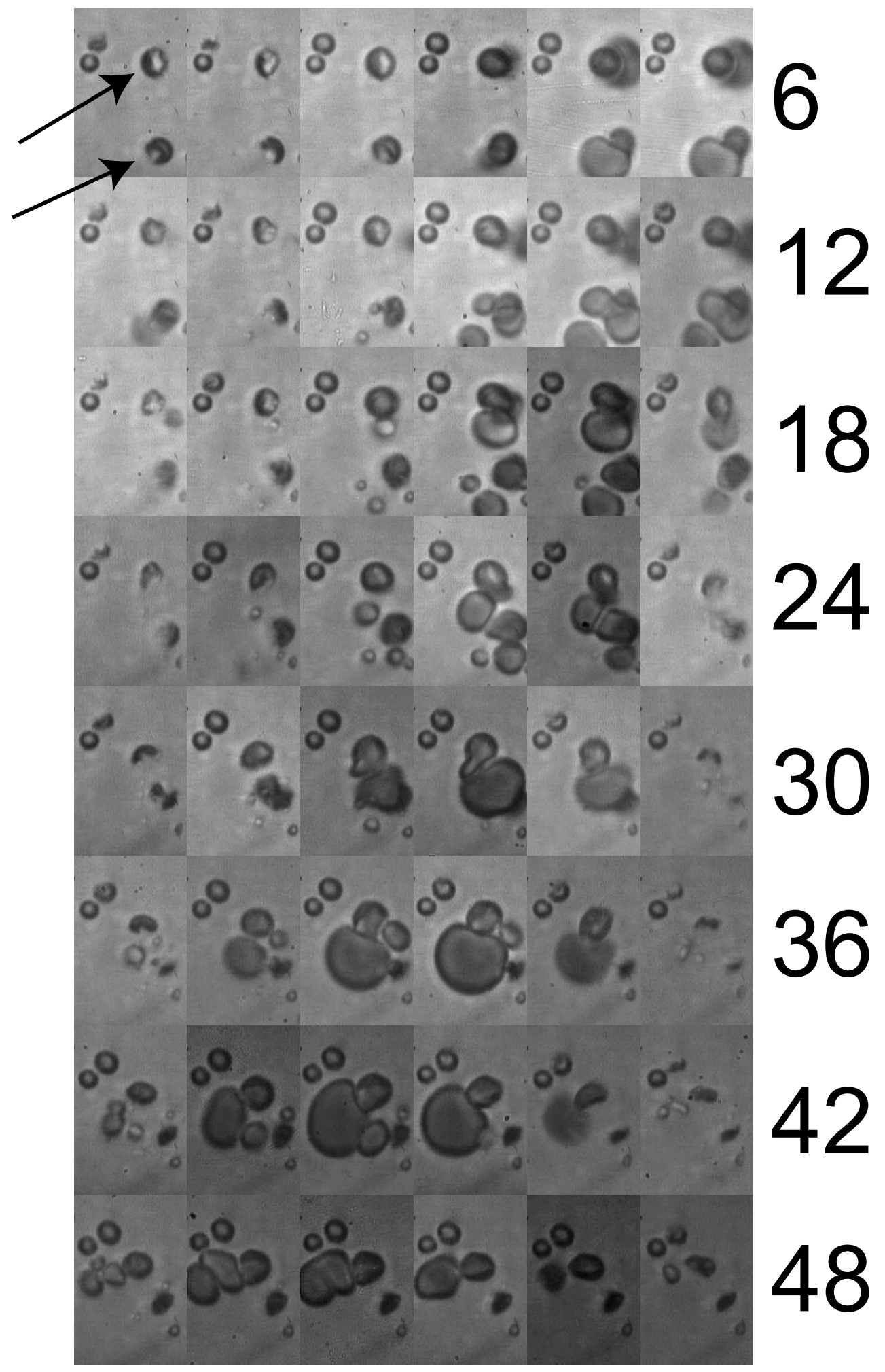

Fig. 9. Gas release from two PB127 contrast microbubbles (arrows) at $1.7 \mathrm{MHz}$ and $\mathrm{MI}=0.9$. Each frame corresponds to a $46 \times 30 \mu \mathrm{m}^{2}$ area. Interframe times are $0.1 \mu \mathrm{s}$. After release (first three rows), the free gas bubbles interact, until one free gas bubble remains (last row). 


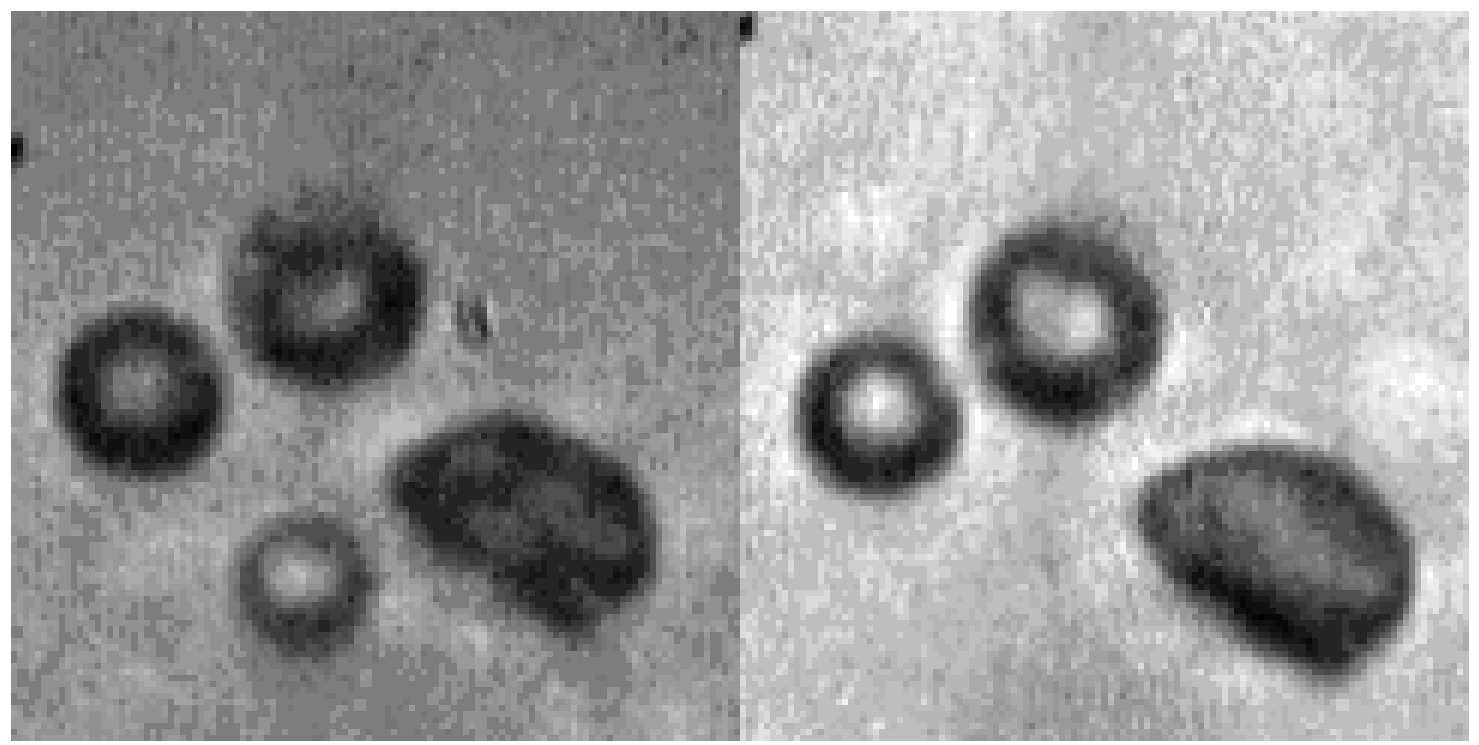

Fig. 10. Three PB127 bubbles and one released gas bubble (left). After $100 \mathrm{~ms}$ the released gas bubble has disappeared (right). Each frame corresponds to a $23 \times 23 \mu \mathrm{m}^{2}$ area. Time between recordings is $100 \mathrm{~ms}$. 


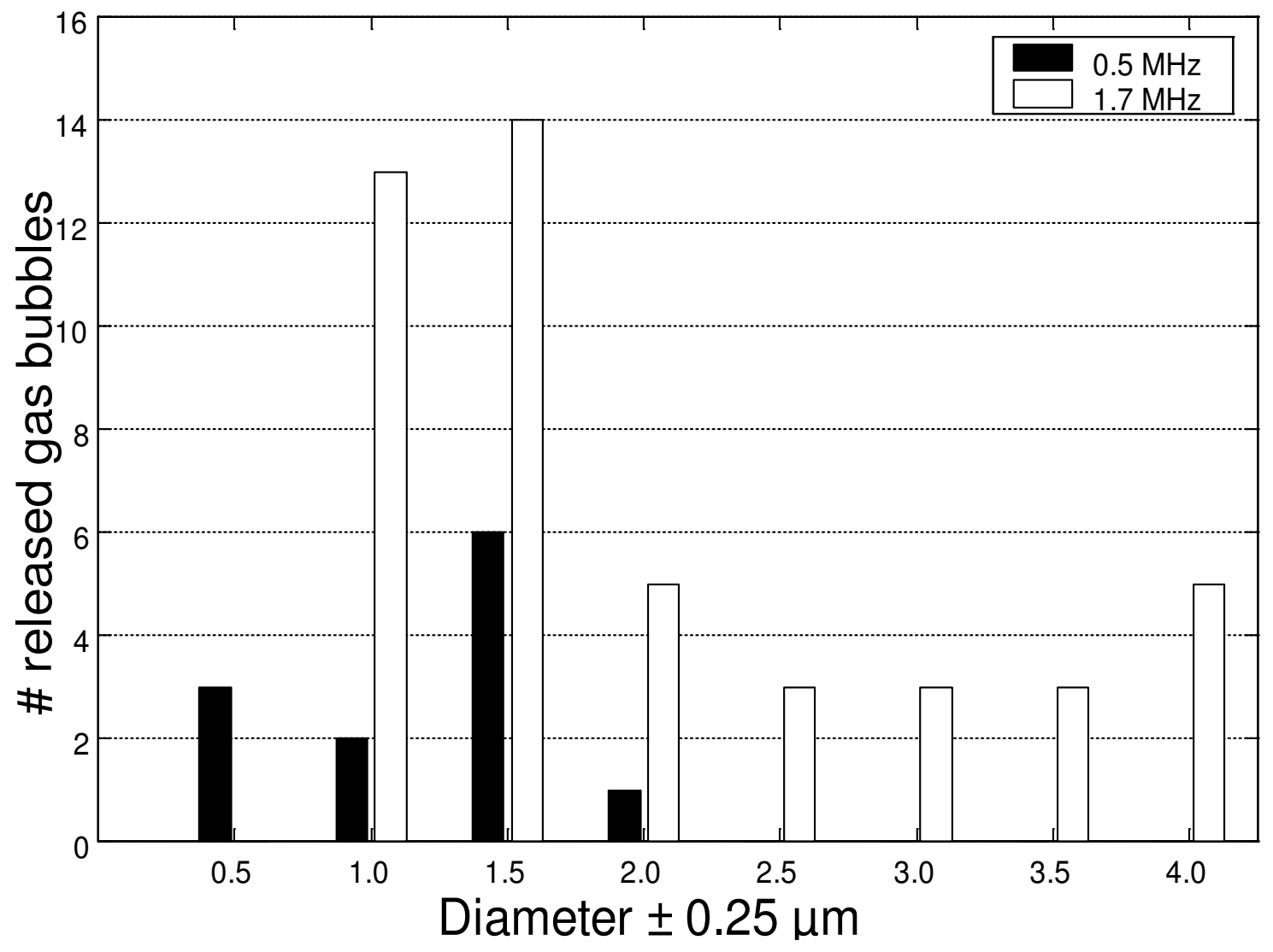

Fig. 11. Size distribution of released gas from PB127 for MI > 0.3. 


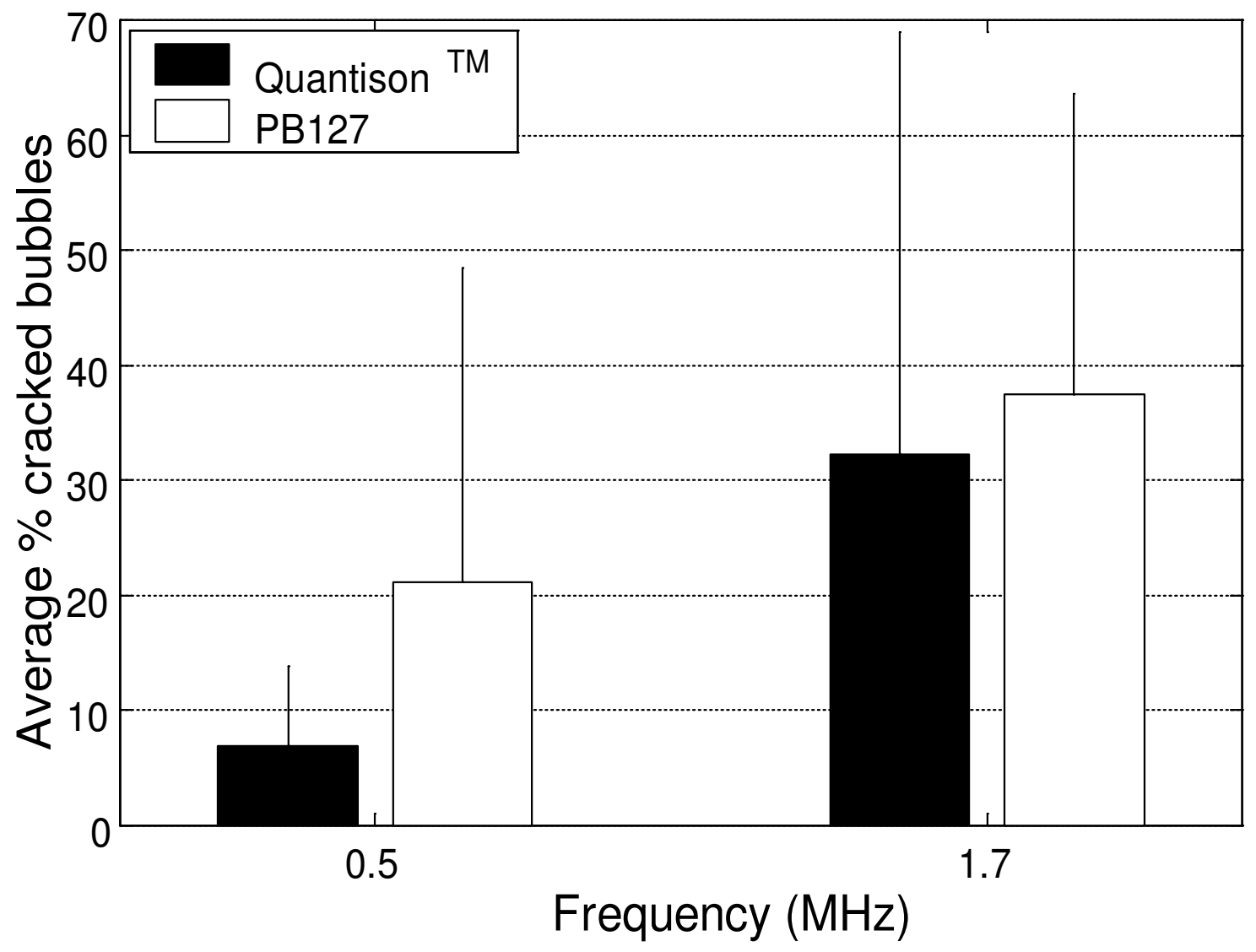

Fig. 12. Average number of cracked contrast agent bubbles for MI $>0.8$. 


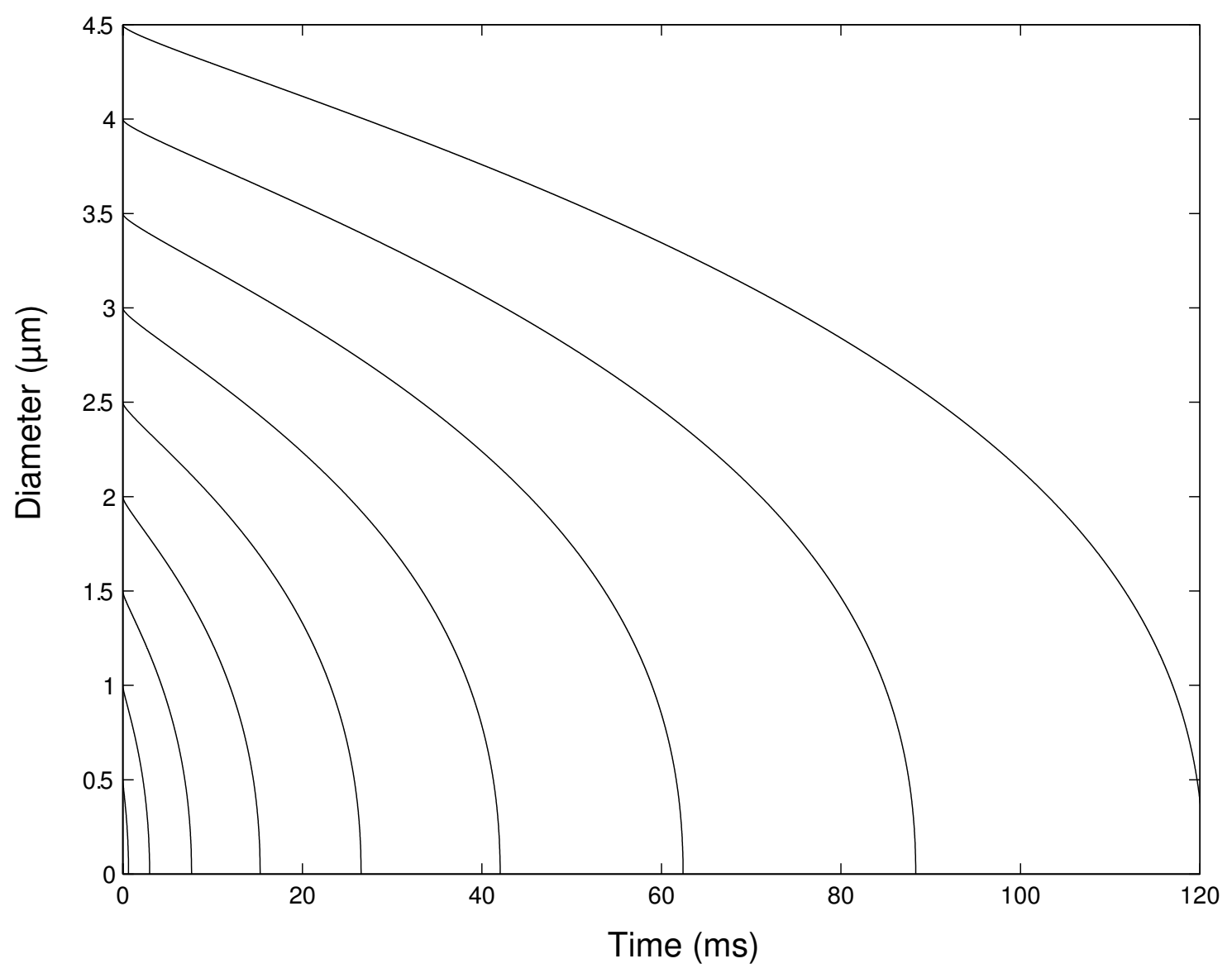

Fig. 13. Dissolution of nitrogen microbubbles with diameters between 0.5 and $4.5 \mu \mathrm{m}$ into saturated water at ambient pressure. 